\title{
Infographic: intravitreous aflibercept vs vitrectomy with panretinal photocoagulation for vitreous haemorrhage from proliferative diabetic retinopathy
}

\author{
Anna Song $\mathbb{D}^{1} \cdot$ Ali Ghareeb ${ }^{1} \cdot$ Alexander Mehta $\mathbb{D}^{1} \cdot$ Salman Naveed Sadiq $^{1} \cdot$ Mohaimen Al-Zubaidy $^{1}$.

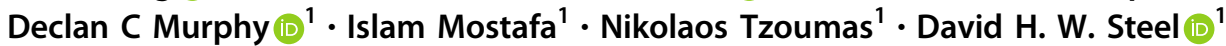

Received: 20 March 2021 / Revised: 26 March 2021 / Accepted: 31 March 2021 / Published online: 26 May 2021

(c) The Author(s) 2021. This article is published with open access

Intravitreous Aflibercept vs

Vitrectomy with Panretinal Photocoagulation for

Vitreous Haemorrhage from Proliferative Diabetic

Retinopathy

Multi-Centre Randomised Clinical Trial by the DRCR Retina Network

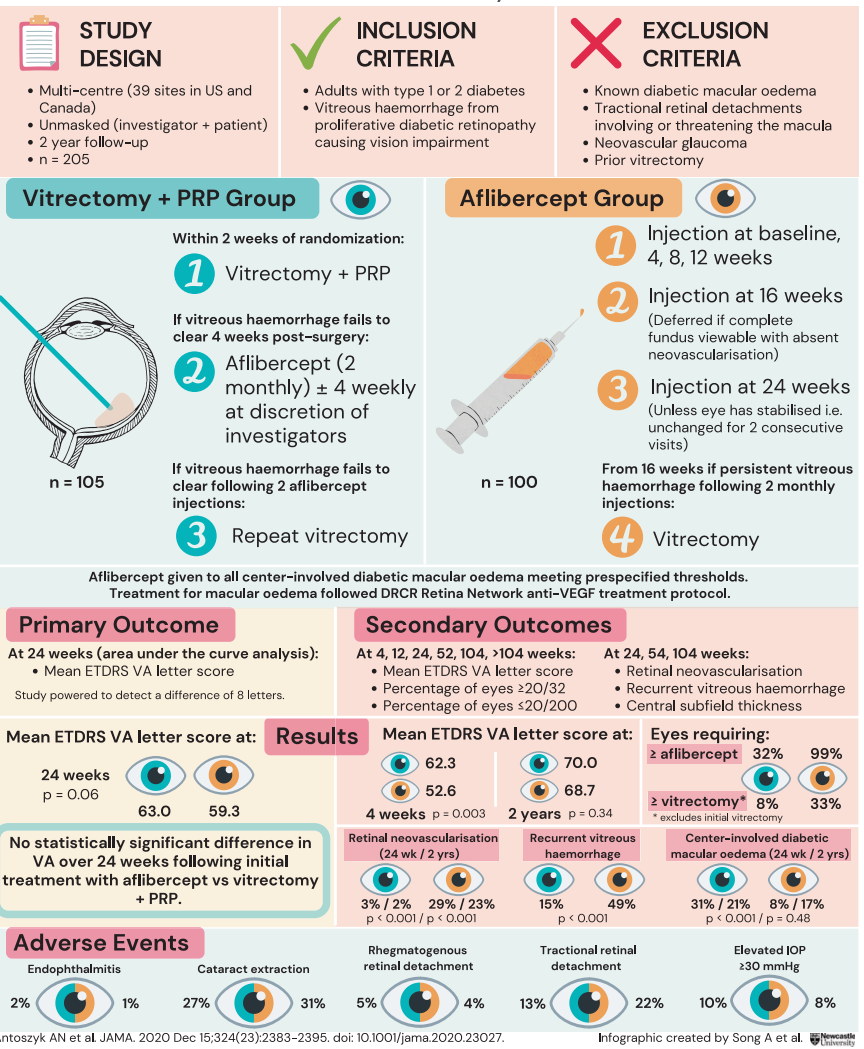

David H. W. Steel

david.steel@ncl.ac.uk

1 Biosciences Institute, Newcastle University, Newcastle upon

Tyne, UK 
Fig. 1 The intravitreous aflibercept vs vitrectomy with panretinal photocoagulation for vitreous haemorrhage from proliferative diabetic retinopathy randomised clinical trial by the DRCR Retina Network showed that there was no statistically significant difference in visual acuity at 24 weeks following initial treatment with aflibercept compared to vitrectomy with panretinal photocoagulation. PRP panretinal photocoagulation, DRCR Diabetic Retinopathy Clinical Research, ETDRS Early Treatment Diabetic Retinopathy Study, VA visual acuity.

Reference to original study: Antoszyk AN, Glassman AR, Beaulieu WT, Jampol LM, Jhaveri CD, Punjabi OS, et al.; DRCR Retina Network. Effect of Intravitreous Aflibercept vs Vitrectomy With Panretinal Photocoagulation on Visual Acuity in Patients With Vitreous Hemorrhage From Proliferative Diabetic Retinopathy: A Randomized Clinical Trial. JAMA. 2020 Dec 15;324(23):2383-2395.

Author contributions AS designed and drafted the infographic. All contributing authors were involved in providing feedback and finalisation of the work.

\section{Compliance with ethical standards}

Conflict of interest The authors declare no competing interests.

Publisher's note Springer Nature remains neutral with regard to jurisdictional claims in published maps and institutional affiliations.

Open Access This article is licensed under a Creative Commons Attribution 4.0 International License, which permits use, sharing, adaptation, distribution and reproduction in any medium or format, as long as you give appropriate credit to the original author(s) and the source, provide a link to the Creative Commons license, and indicate if changes were made. The images or other third party material in this article are included in the article's Creative Commons license, unless indicated otherwise in a credit line to the material. If material is not included in the article's Creative Commons license and your intended use is not permitted by statutory regulation or exceeds the permitted use, you will need to obtain permission directly from the copyright holder. To view a copy of this license, visit http://creativecommons. org/licenses/by/4.0/. 